\title{
Volcanic Evolution of the Kaua'i Shield, Northern Hawaiian Islands
}

\author{
Nicole M.B. Williamson, DominiQue Weis, \\ JAMES S. SCOATES \\ PCIGR, Earth, Ocean and Atmospheric Sciences, University \\ of British Columbia, Vancouver, BC, V6T1Z4, Canada; \\ nwilliam@eoas.ubc.ca, dweis@eoas.ubc.ca, \\ jscoates@eoas.ubc.ca
}

Hawai 'i's northernmost island, Kaua'i ( $\sim 5 \mathrm{Ma})$, has a complex geological history ${ }^{[1]}$ that is different from the typical pairedvolcano configuration of the younger Hawaiian Islands. Kaua ' $i$ appears to consist of a single volcanic centre with an unusually large caldera and a gravity anomaly offset from this caldera to the east $\mathrm{t}^{[1,2,3]}$. Previous studies of Kaua' $\mathrm{i}$ shield-stage geochemistry have shown that lavas in the west part of the island have an isotopic composition distinct from those in the east (Kea vs. Loa) and that these compositions are geographically flipped relative to those on the younger Hawaiian Islands ${ }^{[\text {e.g., } 4,5]}$. To gain insight into the relationship between the geology and geochemistry of Kaua'i shield lavas, 44 new samples were analysed for major element oxide and trace element concentrations and for $\mathrm{Pb}-\mathrm{Sr}-\mathrm{Nd}-\mathrm{Hf}$ isotopic compositions, 90 olivine compositions were measured in nine samples, and 10 samples were dated by ${ }^{40} \mathrm{Ar} /{ }^{39} \mathrm{Ar}$ geochronology. The results show a change in geochemistry and olivine composition from west to east that coincides with an age progression from older to younger. West Nāpali is older and has a Kea-like composition, whereas east Nāpali is younger and is Loa-like; the geographically central units (Olokele and Makaweli) are transitional in both chemistry and age. Thus, the west and east portions of the Nāpali shield-stage volcanic unit formed at different times and sample different heterogeneities in the mantle source. These results have important implications for the sequence of geologic events on Kaua'i. It is possible that both the Olokele caldera and Makaweli graben formed before the bulk of the eastern Nāpali lavas were erupted. As a result, the Nāpali lavas in eastern Kaua' $i$ would have been emplaced near the end of the shield stage and may have been fed by a magma reservoir located where the present-day gravity anomaly in eastern Kaua' $i$ is situated.

[1] MacDonald et al. (1964) Haw. Div. Hydro. Bull. 13, 212pp. [2] Flinders et al. (2010) J. Geophys. Res. 115, B08412. [3] Sherrod et al. (2015) Geophys. Mon. 208, 105-123. [4] Garcia et al. (2010) J.Pet. 51, 1507-1540. [5] Williamson et al. (2019) Geochem. Geophys. Geosys. 20, 4354-4369. 